Proceedings of SALT 22: 188-207, 2012

\title{
Temporal reference in a genuinely tenseless language: the case of Hausa *
}

\author{
Anne Mucha \\ University of Potsdam
}

\begin{abstract}
In this paper, we provide an analysis of temporality in Hausa (Chadic, Afro-Asiatic). By testing the hypothesis of covert tense (Matthewson 2006) against empirical data, we show that Hausa is genuinely tenseless in the sense that the grammar does not restrict the relation between reference time and utterance time. Rather, temporal reference is pragmatically inferred from aspectual and contextual information. We also argue that future time reference in Hausa is realized as a combination of a modal operator and a prospective aspect, thus involving the modal meaning components of intention and prediction as well as event time shifting.
\end{abstract}

Keywords: Temporal Reference, Modality, Hausa, Tenseless Languages

\section{Introduction}

Hausa is a West Chadic SVO tone language spoken by about 35 million people (mainly) in Nigeria and the south of Niger. Its temporal system, which is the subject of this study, is commonly classified as aspect-prominent. However, the descriptive literature also identifies one tense category which is supposed to be encoded in the morpheme $z \bar{a}$ (Newman 2000; Jaggar 2001). The starting point of the following study is the observation that in Hausa, finite matrix sentences such as (1) can in principle get past, present and future interpretations. ${ }^{1}$

* First and foremost, many thanks to my Hausa consultants Yusuf Baba Gar, Idris Amin and Mu'awiya Jibir for providing the data presented in this paper. For essential input and advice, I am especially grateful to Malte Zimmermann. I would also like to thank Radek Šimik, Clemens Mayr, Katharina Hartmann, a reviewer of Linguistics \& Philosophy as well as the participants of SALT and the Potsdam semantics colloquium for helpful reviews and comments on this material. Naturally, any remaining mistakes are my own.

1 The following glosses are used for examples from Hausa: HAB = habitual, $\mathrm{PROG}=$ progressive, PFV $=$ perfective, $\mathrm{POT}=$ potential, $\mathrm{SBJV}=$ subjunctive, $\mathrm{F}=$ feminine, $\mathrm{M}=$ masculine, $\mathrm{PL}=$ plural, $\mathrm{SG}=$ singular, $\mathrm{PREP}=$ preposition, $\mathrm{REL} . \mathrm{PROG}=$ relative progressive, $\mathrm{REL} . \mathrm{PFV}=$ relative perfective, $\mathrm{NEG}=$ negation, DEF = definite. Following convention, long vowels are indicated by macrons, low tones are marked with graves and high tones are not indicated.

C2012 Anne Mucha 
Temporal Reference in Hausa

(1)

Hàwwa tanà wàsā.

Hàwwa 3 SG.F.PROG play

'Hàwwa is / ?was / ??will be playing.'

As indicated by the question marks, these interpretations are not all equally acceptable for native speakers when presented out of the blue. Hence, the matter of investigation is how temporal interpretation is restricted in Hausa, i.e.: (i) What reference time locations are licit under what circumstances? (ii) (How) do aspect morphology and contextual information influence the location of the reference time? (iii) How is future time reference obtained? Following Reichenbach (1947), Klein (1994) and many others, we assume that temporal interpretation involves a threefold distinction between the time at which a sentence is uttered (= UT for "utterance time"), the time at which an eventuality is located (= ET for "eventuality time") and the time about which the speaker makes a claim (= RT for "reference time"). According to Klein (1994), tense relates UT and RT, thus restricting the time interval that the speaker's claim is confined to with respect to the utterance time. Aspect defines a relation between RT and ET, which essentially means defining a temporal viewpoint on an eventuality. The paper is structured as follows: Section 2 identifies two major approaches to the analysis of languages without overt tense morphology, namely one according to which temporal interpretation is restricted by covert tense morphology (Matthewson 2006) and one under which aspectual and contextual information alone determine the location of the reference time of a sentence (Smith \& Erbaugh 2005; Smith et al. 2003, 2007; see also Tonhauser 2011b). Section 3 is the core part of the paper. After giving a brief overview of the tense-aspect-mood (TAM) system of Hausa as it is described in the reference grammars, the pertinent data is presented. Based on these data, we arrive at the conclusion that a tenseless analysis in the spirit of Smith et al. 2003, 2007 accounts for the observations most appropriately, since temporal interpretation is fully predictable from aspect, context and some basic principles of pragmatic reasoning. Subsection 3.1 deals with past and present interpretations specifically. Since, however, special attention is given to future time reference, this is discussed in a separate subsection (3.2). Finally, section 4 summarizes the findings and gives an outlook on further research and conceivable cross-linguistic generalizations.

\section{Two analytical options}

\subsection{A tensed analysis of Hausa}

Some languages without overt tense morphology have been analyzed as encoding tense covertly in their structure. For example, Jóhannsdóttir \& Matthewson (2008) provide a tensed analysis for Gitksan, and Tonhauser (2011b) explores the option 
of covert tense in Paraguayan Guaraní (although she ends up concluding that an analysis without covert tense is to be preferred for this language). For illustrating the main idea, though, we refer to the original proposal made in Matthewson 2006 for St'át'imcets. The crucial data motivating the assumption of a covert tense morpheme are of the following kind:

$$
\begin{array}{ll}
\text { say'sez'-lhkán } & \text { Matthewson (2006: 676) } \\
\text { play-1 SG.SUBJ } & \\
\text { 'I played / I am playing.' } & \\
\text { *say'sez-lhlkán natcw I zánucwem } & \text { Matthewson (2006: 677) } \\
\text { play-1SG.SUBJ one.day.away / next.year } & \\
\text { Intended: 'I will play tomorrow / next year.' } &
\end{array}
$$

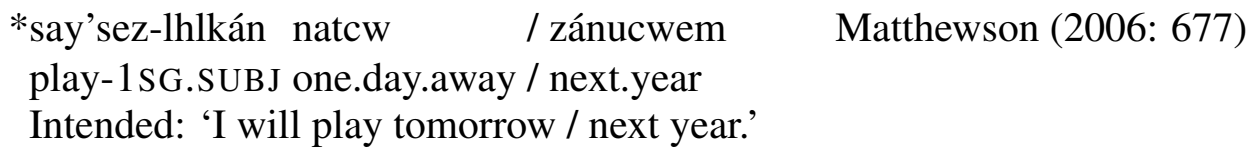

As shown in example (2), finite sentences can get past and present interpretations in St'át'imcets. Crucially, however, future interpretations are excluded. Therefore, adding a future adverbial leads to ungrammaticality, as illustrated in (3). According to Matthewson, future time reference in St'át'imcets requires overt marking, most commonly by the morpheme kelh, as shown in (4).

$$
\begin{aligned}
& \text { say’sez’-lhkán kelh } \\
& \text { play-1SG.SUBJ kelh }
\end{aligned}
$$

Matthewson (2006) also shows that tense interpretation is independent of grammatical aspect in St'át'imcets, while lexical aspect induces preferences, but does not determine tense interpretation either. As for viewpoint aspect, the author reports that all unmarked sentences in St'át'imcets are perfective and that these unmarked sentences like (2) as well as sentences marked for imperfective aspect such as (5) freely receive past and present interpretations.

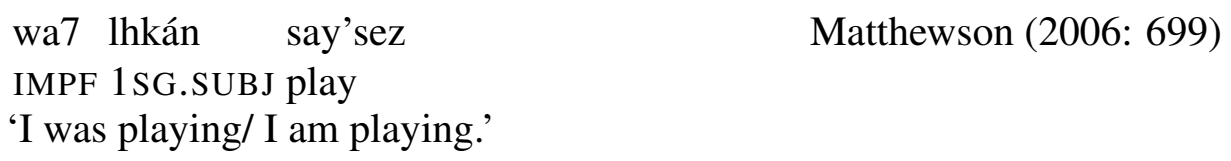

Matthewson (2006: 699)

Matthewson accounts for these observations as follows: She proposes that future time reference in superficially tenseless sentences is excluded because St'át'imcets does in fact encode tense in the grammar, albeit covertly. She assumes that a phonologically null TENSE morpheme restricts temporal reference of every finite clause to a time interval that coincides with or precedes the utterance time. Assuming a pronominal approach to tense (Partee 1973; Kratzer 1998), this reduces the difference between tense in English and tense in St'át'imcets to overt or covert phonological realization and the specificity of the presuppositional restriction (e.g. RT before UT in the 
Temporal Reference in Hausa

case of English PAST and RT not after UT in the case of St'át'imcets TENSE). For illustration, (6) shows the lexical entry that Matthewson adopts for the English PAST morpheme, and (7) gives the meaning she attributes to TENSE in St'át' imcets.

$\llbracket \mathrm{PAST}_{i} \rrbracket^{g, c}$ is only defined if $\mathrm{g}(\mathrm{i})<\mathrm{t}_{c}$ (the utterance time).

If defined, $\llbracket \mathrm{PAST}_{i} \rrbracket^{g, c}=\mathrm{g}(\mathrm{i})$.

[TENSE $i \rrbracket^{g, c}$ is only defined if no part of $\mathrm{g}(\mathrm{i})$ is after $\mathrm{t}_{c}$.

If defined, $\llbracket \mathrm{TENSE}_{i} \rrbracket^{g, c}=\mathrm{g}(\mathrm{i})$.

Future time reference in St'át'imcets involves the combination of this covert TENSE morpheme and the enclitic kelh (see (4)) which Rullmann et al. (2008) analyze as a modal element with a prospective aspectual meaning component as shown in (8). Hence, kelh quantifies universally over a presupposed circumstantial modal base (and also presupposes a choice function that accounts for possibility readings despite universal quantification) but at the same time, it specifies a time interval $t$ ' after the reference time $t$ at which the eventuality in question is located.

\section{Semantics of kelh}

(Rullmann et al. 2008: 341)

$\llbracket k e l h \rrbracket^{c, w, t}$ is only defined if c provides a circumstantial modal base B. $\llbracket k e l h \rrbracket^{c, w, t}=\lambda f_{\langle s t, s t\rangle} \cdot \lambda p_{\langle s,\langle i, t\rangle\rangle} \cdot \forall \mathrm{w}^{\prime}\left[\mathrm{w}^{\prime} \in \mathrm{f}(\mathrm{B}(\mathrm{w}, \mathrm{t})) \rightarrow \exists \mathrm{t}<\mathrm{t}^{\prime} \wedge \mathrm{p}\left(\mathrm{w}^{\prime}\right)\left(\mathrm{t}^{\prime}\right)\right]$

To conclude this subsection, we sum up the predictions that the tensed approach makes for Hausa. Thus, if Hausa works like St'át'imcets we expect that...

i. Grammatical viewpoint aspect does not determine tense interpretation.

ii. Future time reference requires overt marking and is therefore excluded from temporally unmarked finite sentences.

iii. Future marking involves quantification over possible worlds (i.e. modality) and aspectual shifting of the eventuality time.

Notice that only prediction (ii.) emerges directly from the assumption of covert tense morphology. The exclusion of future time reference from finite matrix clauses is the crucial fact that Matthewson's TENSE morpheme captures. Hence, we will consider the availability of future readings without overt future marking as crucial evidence for or against the presence of covert tense morphology in Hausa as well.

\subsection{A tenseless analysis of Hausa}

A second possibility is that temporal interpretation in a seemingly tenseless language is not restricted by tense at all but relies solely on information provided lexically, 
by discourse context and viewpoint aspect, as well as on pragmatic reasoning. One such analysis is provided in Smith \& Erbaugh 2005 for Chinese and in Smith et al. 2003, 2007 for Navajo. The main idea is that temporal interpretation is guided by aspectual information as provided by viewpoint aspect and/or the Aktionsart of the sentence predicate. From these aspectual properties the tense interpretation of a sentence can be deduced with the aid of the following four pragmatic principles:

i. The Deictic Principle: Situations are located with respect to speech time.

ii. The Bounded Event Constraint: Bounded events are not located in the present.

iii. The Simplicity Principle of Interpretation: Choose the interpretation that requires the least information added or inferred.

iv. Temporal Schema Principle: Interpret zero-marked clauses according to the temporal schema of the situation expressed.

The notion of boundedness is central to this approach. Eventualities are temporally bounded if they are either marked for perfective aspect (since that makes the boundaries of an event "visible") or if they are telic, i.e. they have an inherent endpoint and are therefore interpreted as bounded by default. Due to the Bounded Event Constraint, these eventualities are not located in the present; the reason being, as Smith \& Erbaugh (2005) put it, that "[...] speakers follow a tacit convention that communication is instantaneous. The perspective of the present time is incompatible with a bounded event, because the bounds would go beyond that perspective." Under the assumption that future interpretation is more complex than past interpretation due to the additional (modal) component of uncertainty that comes with it, the Simplicity Principle of Interpretation predicts that temporally bounded events are located in the past rather than in the future. An example from Navajo, which involves perfective morphology and hence gets a past interpretation by default is given in (9) (Smith et al. 2007: 59).

$$
\begin{aligned}
& \text { Shimá ch'iyáán ła’ bá naháłnii' } \\
& \text { 1-mother groceries some 3-for PERF-1SUBJ-PERF-BUY } \\
& \text { 'I bought some groceries for my mother.' }
\end{aligned}
$$

As for imperfective and progressive sentences, the Deictic Principle and the Simplicity Principle taken together predict that those should be located in the present. Like aspectually unmarked atelic predicates (i.e. activities and states in the terminology of Vendler 1957), they are classified as temporally unbounded. Thus, their temporal 
Temporal Reference in Hausa

boundaries are not included in the aspectual viewpoint of the speaker, which is compatible with the described (part of the) situation including the moment of utterance. Sentence (10) shows a relevant example from Navajo:

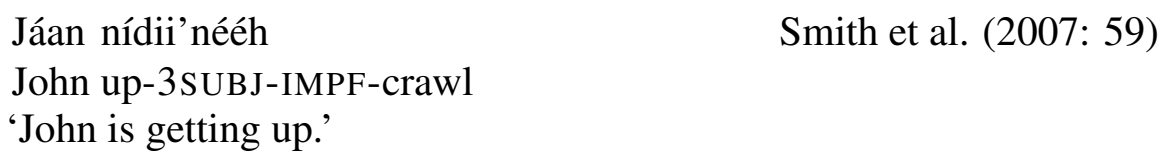

Again, to conclude this subsection, we sum up the major predictions that the tenseless approach makes for Hausa.

i. Sentences marked for perfective are interpreted in the past by default.

ii. Sentences marked for imperfective/progressive are interpreted in the present by default.

iii. Future time reference is overtly marked (since, due to its additional modal component, it never arises as default) but it is not categorically excluded from unmarked sentences.

Hence, ultimately, the empirical questions to ask when it comes to an analysis of Hausa are: (i) Does aspect influence the location of RT and (if so) how? (ii) Is future time reference possible in finite sentences and (if so) under which circumstances? (iii) Is there evidence for a modal and/or aspectual component in the realm of future time reference? In section 3, we provide data to shed some light on these issues.

\section{Temporal reference in Hausa}

\subsection{The TAM-system of Hausa}

In this section, we give a brief overview on the tense-aspect-mood (TAM) system of Hausa as it is described in the pertinent literature (e.g. Newman 2000; Jaggar 2001; Wolff 1993). The prevailing view is that Hausa marks aspect predominantly, but also encodes mood and (future) tense. It is notable in this context that TAM properties are marked obligatorily in a single paradigm and that the TAM markers form a morphological complex with preverbal weak subject pronouns. In what follows, we provide an example adopted from Schuh (2003) of each of the TAM forms under consideration. ${ }^{2}$ The first one is the perfective aspect which expresses

2 Note that this enumeration is not exhaustive. Among the TAM forms that have been omitted, there are at least two for which our own fieldwork provided evidence and which are ignored here only for reasons of space, viz. a habitual and a potential form. The description of the other TAM categories is essentially adopted from Newman 2000 with the minor alteration of using the terms perfective and progressive instead of completive and continuous. For a detailed description of the Hausa TAM 
temporal boundedness.

$$
\begin{aligned}
& \text { Sun gudù } \\
& \text { 3PL.PFV run } \\
& \text { 'They ran.' }
\end{aligned}
$$

The progressive aspect is a combination of a light-syllable weak subject pronoun and the TAM marker $-n \bar{a}$, indicating ongoing action or durativity. ${ }^{3}$

$$
\begin{aligned}
& \text { Sunà gudù } \\
& \text { 3PL.PROG run } \\
& \text { 'They are running.' }
\end{aligned}
$$

The so-called subjunctive consists of bare light-syllable pronouns with a low tone.

$$
\begin{aligned}
& \text { Sù gudù } \\
& \text { 3PL.SBJV run } \\
& \text { 'They should run.' }
\end{aligned}
$$

The form that the literature normally refers to as future tense consists of the free morpheme $z \bar{a}$ which precedes the weak subject pronoun and combines with the morphologically unmarked (subjunctive) TAM form.

$$
\begin{aligned}
& \text { Zā sù gudù } \\
& \text { ZĀ 3PL.SBJV run } \\
& \text { 'They will run.' }
\end{aligned}
$$

The remainder of the section is concerned with the behavior of these TAM forms and their impact on tense interpretation. The upshot of the discussion is that neither of them semantically restricts the relation between reference time and utterance time. Section 3.2 presents data motivating the conclusion that there is no tense morphology in the grammatical system of Hausa and that tense interpretation is derived from aspect and context by way of pragmatic reasoning. In section 3.3, we propose that the alleged future marker $z \bar{a}$ encodes modality rather than tense. As a final result, therefore, Hausa is analyzed as encoding no tense in the sense of Klein (1994).

system, the reader is referred to this work.

3 Both the perfective and the progressive form have so-called relative counterparts that occur in relative clauses, questions and focus constructions. Abdoulaye (2008) argues that the relative perfective can have a past tense meaning. For reasons of space, however, this issue is not discussed here. 
Temporal Reference in Hausa

\subsection{Past and present interpretations}

\subsubsection{Default interpretations}

The first observation of interest is that aspect marking in Hausa induces clear default interpretations in accordance with the predictions made by Smith et al. (2007). More precisely, sentences marked for progressive are consistently interpreted in the present when presented out of the blue as shown in (15). Sentences marked for perfective are interpreted in the past (16).

Ali yanà wà̀ā.

Ali 3SG.M.PROG play

'Ali is playing.'

Ali yà $\quad$ yi wàsā.

Ali 3SG.M.PFV do play

'Ali played.'

Without a specific context, speakers reject sentences in which a temporal adverbial restricts the RT location in a way that contradicts the default interpretations. Hence, co-occurrences of the progressive aspect with a past (17) or a future (18) adverbial are judged as odd or outright unacceptable.

??Tanà wà̀ā jiyà.

3SG.F.PROG play yesterday

Intended: 'She was playing yesterday.'

\#Tanà wà̀ā gòbe.
3SG.F.PROG play tomorrow
Intended: 'She will be playing tomorrow.'

Interestingly, some speakers perceive a difference here, namely that progressive sentences containing future adverbials are slightly more degraded than those containing past adverbials, as indicated by the use of "??" and "\#", respectively. When perfective aspect is combined with a present (19) or future (20) adverbial, the judgments are slightly stronger in both cases.

\#Hàwwa tā dafà̀ wākē yànzu.

Hàwwa 3SG.F.PFV cook beans now

Intended: 'Hàwwa cooks/has cooked beans now.'

\#Hàwwa tā dafà̀ wākē gòbe.

Hàwwa 3 SG.F.PFV cook beans tomorrow

Intended: 'Hàwwa will cook beans tomorrow.' 
Importantly, though, these generalizations hold only for isolated sentences. If the utterance context provides a past reference time, progressive sentences get past interpretations without any difficulty.

(21) Context question: What was Hasàn doing when Ali entered his house yesterday?

Lōkàcîn dà Ali ya zō, Hasàn yanà $\quad$ wàsā.

When Ali 3SG.M.REL.PFV come Hasàn 3SG.M.PROG play

'When Ali came, Hasàn was playing.'

As predicted by the Bounded Event Constraint, present interpretations of sentences with perfective aspect are virtually unobtainable. Nonetheless, the combination of perfective aspect and a present adverbial can be licensed in a context which facilitates the sort of recent past event/result state interpretation that is associated with the present perfect in English as illustrated in (22). Notably, Hausa patterns with Navajo in this respect (see Smith et al. 2007).

(22) Context question: I'm starving, is there anything to eat?

Hàwwa tā dafà wākē yànzu.

Hàwwa 3SG.F.PFV cook beans now

'Hàwwa has cooked (finished cooking) beans now.'

Evidence that we are actually dealing with perfective aspect rather than past tense morphology comes from mental state predicates such as know or remember which resemble their English counterparts in that they refuse progressive marking. In their perfective form, they get present interpretations by default.

$$
\begin{aligned}
& \text { Tāa tunà sarai. } \\
& \text { 3sG.F.PFV remember well } \\
& \text { 'She remembers quite well.' }
\end{aligned}
$$

The upshot of this data section is that tense interpretation is systematically guided by the viewpoint aspect marked on the weak subject pronoun. However, these interpretations can be overriden by contextual information and must, therefore, be attributed to pragmatic defaults rather than to hardwired semantic restrictions.

\subsubsection{Future time reference without future marking}

Recall that the main prediction of Matthewson's (2006) tensed analysis is that future time reference is excluded from finite sentences unless it is overtly marked. As shown in (18) and (20), neither progressive nor perfective sentences allow for combination with a future time adverb without a specific context, which is in line 
Temporal Reference in Hausa

with Matthewson 2006. However, similarly to the past and present cases above, progressive (24) as well as perfective (25) aspect is compatible with future time reference if a salient future reference time is provided by the discourse context.

(24) Context question: What will Ali be doing when I come home tomorrow?

Ali yanà wà̀ā gòbe.

Ali 3SG.M.PROG play tomorrow

'Ali will be playing tomorrow (... when you come).'

(25) Context question: Am I supposed to feed the baby tonight?

Kàfin kà iso jàrirìn yā yi barci.

Before 2SG.M.SBJV arrive baby.DEF 3SG.M.PFV do sleep

'When you arrive, the baby will already be asleep.'

Thus the tensed analysis does not make the right predictions for Hausa. Although speakers show clear preferences depending on viewpoint aspect, all RT locations are in principle available for all aspects. Crucially, the observation that this is also true for future time reference, as shown in (24) and (25), sets Hausa apart from languages such as St'át'imcets (Matthewson 2006) and Guaraní (Tonhauser 2011b), where future RTs are reported to be unavailable in cases like (24).

\subsubsection{The analysis: pragmatic resolution of temporal reference}

This section puts forward a tenseless analysis for Hausa that accounts for the facts in (3.2.1) and (3.2.2). First, we adopt a version of Smith et al.'s pragmatic account of temporal interpretation in Navajo with the following ingredients:

- The Bounded Event Constraint (BEC)

(Smith et al. 2007: 45)

Bounded Events are not located in the Present.

In the framework assumed here, the effect of the BEC in Hausa can be described as follows: Perfective aspect morphology enforces temporal boundedness of the eventuality it applies to, i.e. it makes its temporal boundaries "visible". In the definition of Klein (1994) and Kratzer (1998), this means that the eventuality time must be properly included in the reference time. The reference time is therefore not identified with the utterance time since UT is assumed to be instantaneous and can, therefore, not subsume the eventuality time as "the bounds would go beyond the moment" (Smith et al. 2007: 45). As a second step, a hierarchy of temporal interpretations with respect to simplicity is established on the basis of Smith et al.'s (2007: 60) Simplicity Principle of Interpretation in order to account for aspectdependent default interpretations. The final principle, contextual anchoring, captures the overall context dependency of temporal reference in Hausa. 
Anne Mucha

- Hierarchy of Simplicity (HoS) :

i. $\mathbf{R T}=\mathbf{U T}$ : Present time reference is the simplest kind of temporal reference since a) an utterance situation always provides a time interval to which a RT variable can be anchored, namely the utterance time, and b) present interpretation requires no displacement of either the time or the world of evaluation.

ii. RT < UT: Past time reference is more "complex" than present time reference since it requires displacement of the evaluation time from the concrete utterance situation.

iii. RT > UT: Future interpretation also involves reference time shifting and is hence more complex than present interpretation. In contrast to past time reference, however, it adds the complication of modal displacement and thus increases the level of abstraction required for interpreting the utterance. ${ }^{4}$

\section{- Contextual Anchoring (CA)}

Explicit temporal information may override pragmatic defaults. More precisely, if the previous discourse context provides a RT alternative to the pragmatic default, this RT can serve as a temporal anchor for the time variable of the sentence.

With these informal pragmatic assumptions at hand, the data presented above can be explained. Progressive sentences without context (see (15)) get present tense interpretations because, according to the HoS, present tense is the simplest form of temporal reference. Furthermore, if no context is provided, no alternative RT is made salient. The same sentence with perfective aspect (16) gets a past interpretation by default because, according to the BEC, perfective aspect obviates present interpretation and the HoS states that past interpretation is simpler than future interpretation as it does not require modal displacement. A perfective sentence containing a state predicate such as (23), by contrast, is not interpreted in the past despite perfective aspect since for stative predicates, the relevant temporal relation is overlap rather than inclusion (cf. Kamp \& Reyle 1993; Condoravdi 2002). Hence, in the case of states, the eventuality time need not be properly included in the reference time but must overlap with it which supports a present interpretation. If sentences contain temporal adverbials which do not accord with the default interpretations suggested by the viewpoint aspect, appropriate contextual support is needed in

4 Whether future time reference involves reference to possible worlds is a matter of debate. Arguments in favor of a modal analysis of futurity are given e.g. by Enç (1996) and Copley (2009). The opposite view is defended in Kamp \& Reyle (1993) and Kissine (2008), among others. 
order to resolve this conflict. In (17) and (19), no such context is given, hence the sentences are unacceptable. If, by contrast, the context provides a suitable reference time, past (21) and future interpretations (24) with progressive aspect as well as future interpretations with perfective aspect (25) are licit, as captured by the CA-principle. With contextual support, (22) seems to be the closest one can get to a present interpretation with perfective aspect. This suggests that the BEC should be regarded as a semantic constraint following from the meaning of the perfective aspect rather than a mere pragmatic default. Since present RTs as in (22) are assumed to be instantaneous and therefore cannot include the running time of a durative eventuality like to cook beans, the temporal endpoint of the event can maximally abut the reference time, leading to a result state (here: the beans being cooked) which may overlap RT.

\subsection{Future interpretations}

\subsubsection{The behavior of the future marker}

As shown in the preceding section, it is possible in Hausa to refer to future events in the absence of a grammatical future marker. The most natural way to refer to a future time according to native speakers, however, involves the use of the morpheme $z \bar{a}$ which the reference grammars describe as a future tense marker. Interestingly, $z \bar{a}$ deviates from the other TAM markers in that it precedes the weak subject pronoun rather than being suffixed to it.

$$
\begin{aligned}
& \text { Hàwwa zā tà wà̀ā. } \\
& \text { Hàwwa ZĀ 3SG.F.SBJV play } \\
& \text { 'Hàwwa will play.' }
\end{aligned}
$$

Another remarkable property of $z \bar{a}$ is that it seems to be incompatible with aspect marking, as shown in (27) for progressive and in (28) for perfective aspect. Instead of that, $z \bar{a}$ must always occur with the subjunctive TAM form, as is the case in (26).

$$
\text { *Hàwwa zā tanà wà̀ā. }
$$

Hàwwa ZĀ 3SG.F.PROG play

Intended: 'Hàwwa will be playing.'

$$
\begin{aligned}
& \text { *Hàwwa zā tā } \quad \text { wàsā. } \\
& \text { Hàwwa ZĀ } 3 \text { SG.F.PFV play } \\
& \text { Intended: 'Hàwwa will have played.' }
\end{aligned}
$$

As for the temporal meaning of the Hausa future form (i.e. the combination of $z \bar{a}$ and the subjunctive), it arguably shifts the event time rather than the reference 
time. The observation is that $z \bar{a}+s b j v$ is compatible with past as well as present RTs under the condition that the meaning expressed in the sentence is a prediction by or an intention of the speaker or some other salient agent. This is a striking parallel to the meaning of the future marker - $t a$ in Paraguayan Guaraní which Tonhauser (2011a) analyzes as a prospective aspect compatible with the modal meanings of intention and prediction. In (29) this is illustrated for Hausa by a sentence with a past reference time (the day of the weather forecast) from which the event time (i.e. the time of the supposed raining event) is shifted forward. Crucially though, both $\mathrm{RT}$ and $\mathrm{ET}$ are in the past of the utterance time of the sentence.

(29) Context: It is Monday and you are talking about last weekend. You had planned a trip for Sunday, but the weather forecast had predicted rain and it was very cloudy and dark outside. So you cancelled your trip and stayed at home. In the end, not a drop of rain came down. You say:

Jiyà zā à yi ruwa, àmmā bà à yi ba.

Yesterday ZĀ 4.SBJV do rain but NEG.PFV do NEG

'Yesterday, it was going to rain, but then it didn't.'

Similarly, it is possible to combine the future form with a present adverbial in order to express an intention at a present reference time to instantiate some event later on.

(30) Context question: What is Hàwwa up to?

Zā tà wankè kwānukà yànzu.

ZĀ 3SG.F.SBJV wash dishes now

'She will (is planning to) wash the dishes now.'

The last point to note is that the event time shifting associated with the future form also takes place when the subjunctive occurs without $z \bar{a}$. Evidence for the futureshifting effect of the subjunctive is given in (31) and (32). In (31), the Totem Field Storyboard "On the Lam" (TFS working group 2011) was used to elicit presentoriented epistemic modality, which in Hausa is expressed by a combination of the modal adverb watakila and progressive aspect.

(31) Context (presented as a picture story of the TFS): Two police officers are looking for Sue and Peter who are supposedly hiding in a cottage. Having entered the cottage, the officers take a look-around and discuss where Sue and Peter might be hiding from them. One of them says:

Watakila sunà buye (a) cikin wancan àkwàtì.

Perhaps 3PL.PROG hide at in that box

'They could be hiding in that box.' 
Temporal Reference in Hausa

Notably, the sentence is also grammatical when the weak subject pronoun is marked for subjunctive rather than progressive. In this case, however, it is not acceptable in the given context, since it requires that Sue and Peter are not yet in the box at the present RT, as evidenced by the speaker comment on (32). Thus, the interpretation of the sentence must be circumstantial, future-oriented modality.

$$
\begin{aligned}
& \text { \#Watakila sù buye (a) cikin wancan àkwàtì. } \\
& \text { Perhaps 3PL.SBJV hide at in that box } \\
& \text { 'They could hide in that box.' } \\
& \text { Comment: This is only possible if they are not in the box yet, but could } \\
& \text { possibly get in. }
\end{aligned}
$$

Consequently, the combination of $z \bar{a}+s b j v$ does not license non-future epistemic interpretations either, as is illustrated in (33). According to the consultant, this sentence could only be felicitously uttered in a context where Peter is still sick at the present RT, but the speaker wants him to recover immediately so that he can still come to the office before the day is over (i.e. in the near future).

(33) Context: I have just seen Musa in his office. I heard he was sick, so why is he at work?
\#Lalle
zâi
(yi) lāfiyà̀ yâu.
Necessarily ZĀ.3SG.M.SBJV do health today
Intended: 'He will be well (lit.do health) today.'
(no present reading possible)

The future-shifting effect of the subjunctive is also reported in Schuh 2003, where the author refutes the ambiguity analysis for the morphologically unmarked TAM form proposed by Newman (2000) and Jaggar (2001). According to these authors, the subjunctive is distinct from a morphologically identical neutral form which "[...] is found in a number of different constructions in which grammatical specification of tense/aspect is not essential since it is deducible from the sentential or pragmatic context." (Newman 2000: 594). Schuh (2003), however, shows that the morphological form has a unified meaning which he describes as "dependent subsequent inception". That is to say, the unified category for which Schuh retains the label of subjunctive does not in itself express mood, but rather imposes the restriction that "the event expressed by the subjunctive has its inception subsequent to a time implied by context" (Schuh 2003: 26). Thus, according to Schuh, the subjunctive shifts the running time of some eventuality to the future of a contextually given reference time, which is a fairly common definition of prospective aspectuality (see e.g. Comrie 1976; Klein 1994). In addition to its future-shifting effect, Schuh (2003: 20) notes that the subjunctive is underspecified in the sense that the concrete 
temporal or modal interpretation of the event in the subjunctive is dependent on that of a superordinate clause or operator. In our formal analysis of the Hausa future form, we will essentially adopt these insights and show how the data reported above can be derived from them.

\subsubsection{A decomposed analysis of the future in Hausa}

In this section, our analysis of the meaning components of the Hausa TAM usually referred to as future tense is spelled out formally. Following ideas of Enç (1996) and Tonhauser (2011a), we argue that the Hausa future form conveys the inherently future-oriented meanings of intention and prediction. Tonhauser models these meanings for the Guaraní future marker - $t a$ by assuming that it presupposes an epistemic modal base and a stereotypical ordering source (accounting for the meaning of prediction) or a circumstantial modal base and an ordering source specifying the agent's intentions (accounting for the meaning of intention). If this modal presupposition is fulfilled, a time subsequent to the reference time is introduced at which the event is located in all possible worlds that are best with respect to the modal base and the ordering source. We propose that the Hausa future form encodes a similar meaning, but with the semantic components of event time shifting and (modal) quantification split between a modal operator $z \bar{a}$ and a (deficient) prospective aspect traditionally analyzed as subjunctive.

Let us turn to this element (henceforth referred to as prospective) first. On the basis of Schuh 2003 and the data presented in the preceding subsection, three essential properties of this morphological form can be identified: Firstly, the prospective contributes the future-shifting that is associated with the future-form. Secondly, it is the event time that is shifted with respect to the reference time rather than the reference time relative to the utterance time (which would be the restriction imposed by a future tense in the definition of Klein 1994). Thirdly, this prospective aspect is dependent on some superordinate quantificational element. The lexical entry by which we would like to model these properties is given in (35). We adopt a formalization of aspect proposed in Kratzer 1998 according to which aspect encodes existential quantification over eventualities and a temporal relation between the eventuality time $\tau(e)$ and the reference time $t$.

$$
\text { [perfective] }]^{g}=\lambda P_{\langle l\langle s t\rangle\rangle} \cdot \lambda t \cdot \lambda w \cdot \exists e[P(e)(w) \& \tau(e) \subseteq t]
$$

In contrast to the perfective aspect, the sole semantic contribution of the prospective in Hausa consists in a future shifting of the eventuality time $\tau(e)$ with respect to the reference time $t$ (which leads us to break with the established terminology here). The underspecification of the concrete modal and temporal localization of the eventuality is modeled in the form of an open event variable in the lexical entry of 
Temporal Reference in Hausa

the prospective, which must then be bound by some operator higher in the structure. ${ }^{5}$

$$
\text { [prospective }]^{g}=\lambda P_{\langle l\langle s t\rangle\rangle} \cdot \lambda e \cdot \lambda t \cdot \lambda w \cdot[P(e)(w) \& \tau(e)>t]
$$

$Z \bar{a}$ is analyzed as an idiosyncratic modal operator "hosting" the prospective, i.e. it encodes (universal) quantification over possible worlds and existentially binds the open event variable of the prospective.

$$
\llbracket[\mathrm{z} \overline{\mathrm{a}} \rrbracket]^{g}=\lambda P_{\langle l\langle i\langle s t\rangle\rangle\rangle} \cdot \lambda t . \lambda w \cdot \forall w^{\prime}\left[w^{\prime} \in M A X_{O_{(w)(t)}}(M B(w)(t)) \rightarrow \exists e\left[P(e)(t)\left(w^{\prime}\right)\right]\right]
$$

Thus, the ungrammaticality of $z \bar{a}$ and (other) aspects can be attributed to a type mismatch. The operator $z \bar{a}$ requires an argument of type $\langle l\langle i\langle s t\rangle\rangle\rangle$ (i.e. a relation between events and times) and is hence incompatible with aspects denoting properties of times such as the perfective. For illustration, the denotation of the future sentence in (26) with the LF in (37) is given in (38).

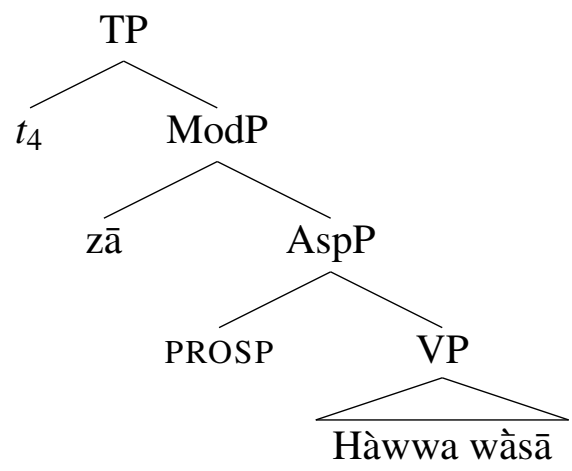

(38)

$$
\begin{aligned}
& {\left[[\mathrm{VP}]^{g}=\lambda \mathrm{e} . \lambda \mathrm{w} \cdot[\mathrm{play}(\mathrm{e})(\mathrm{w}) \& \text { agent }(\operatorname{Hàwwa})(\mathrm{e})(\mathrm{w})]\right.} \\
& \llbracket \text { AspP } \rrbracket^{g}=\llbracket \mathrm{PROSP} \rrbracket^{g}\left(\llbracket \mathrm{VP} \rrbracket^{g}\right) \\
& =\left[\lambda P_{\langle l\langle s t\rangle\rangle} \cdot \lambda \mathrm{e} \cdot \lambda \mathrm{t} \cdot \lambda \mathrm{w} \cdot[\mathrm{P}(\mathrm{e})(\mathrm{w}) \& \tau(\mathrm{e})>\mathrm{t}]\right](\lambda \mathrm{e} \cdot \lambda \mathrm{w} \cdot[\mathrm{play}(\mathrm{e})(\mathrm{w}) \\
& \& \text { agent (Hàwwa)(e)(w)]) } \\
& =\lambda \text { e. } \lambda \mathrm{t} \cdot \lambda \mathrm{w} \cdot[\mathrm{play}(\mathrm{e})(\mathrm{w}) \& \operatorname{agent}(\operatorname{Hàwwa})(\mathrm{e})(\mathrm{w}) \& \tau(\mathrm{e})>\mathrm{t}] \\
& {\left[[\operatorname{ModP}]^{g}=\llbracket\left[\mathrm{za} \rrbracket^{g}(\llbracket \mathrm{AspP}]^{g}\right)\right.}
\end{aligned}
$$

5 Sometimes, this operator is phonologically empty as the prospective can also occur without an overt quantificational element scoping directly over it. Since in these cases it normally receives an imperative interpretation, as exemplified in (i), we tentatively assume some version of Kaufmann's (2012) modal operator $O P_{\text {Imp }}$, although details remain to be worked out.

$$
\begin{aligned}
& \text { Kù tāshì } \\
& \text { 2sG.PROSP get.up } \\
& \text { 'Get up!' }
\end{aligned}
$$

Newman (2000: 591) [our glossing] 


$$
\begin{aligned}
& =\left[\lambda P_{\langle l\langle i\langle s t\rangle\rangle\rangle} \cdot \lambda \mathrm{t} \cdot \lambda \mathrm{w} . \forall \mathrm{w}^{\prime}\left[\mathrm{w}^{\prime} \in M A X_{O_{(w) t t)}}(\mathrm{MB}(\mathrm{w})(\mathrm{t})) \rightarrow \exists \mathrm{e}\left[\mathrm{P}(\mathrm{e})(\mathrm{t})\left(\mathrm{w}^{\prime}\right)\right]\right]\right] \\
& (\lambda \text { e. } \lambda \text { t. } \lambda \text { w.[play(e)(w) } \& \operatorname{agent}(\operatorname{Hàwwa})(\mathrm{e})(\mathrm{w}) \& \tau(\mathrm{e})>\mathrm{t}]) \\
& =\lambda \mathrm{t} . \lambda \mathrm{w} . \forall \mathrm{w}^{\prime}\left[\mathrm { w } ^ { \prime } \in \operatorname { M A X } _ { O _ { ( w ) ( t ) } } ( \mathrm { MB } ( \mathrm { w } ) ( \mathrm { t } ) ) \rightarrow \exists \mathrm { e } \left[\text { play }(\mathrm{e})\left(\mathrm{w}^{\prime}\right) \& \operatorname{agent}(\text { Hàwwa })\right.\right. \\
& \left.\left.(\mathrm{e})\left(\mathrm{w}^{\prime}\right) \& \tau(e)>t\right]\right] \\
& \llbracket \mathrm{TP}]^{g}=\lambda \mathrm{w} . \forall \mathrm{w}^{\prime}\left[\mathrm { w } ^ { \prime } \in M A X _ { O _ { ( w ) ( g ( 4 ) ) } } ( \mathrm { MB } ( \mathrm { w } ) ( \mathrm { g } ( 4 ) ) ) \rightarrow \exists \mathrm { e } \left[\text { play }(\mathrm{e})\left(\mathrm{w}^{\prime}\right) \&\right.\right. \\
& \operatorname{agent}(\text { Hàwwa)(e)(w’) \& } \tau(\mathrm{e})>\mathrm{g}(4)]]^{6}
\end{aligned}
$$

Thus, (26) is true iff in all worlds w' that are accessible from the ordering $\mathrm{O}$ on the modal base MB there is an event of Hàwwa playing and the running time of this event is subsequent to a contextually provided reference time $\mathrm{g}(4)$.

\section{Summary and outlook}

To sum up the central results of this study: We have proposed a tenseless analysis for Hausa based on the observation that aspect-marked sentences receive flexible temporal interpretations. In particular, future readings can be obtained without overt future marking. Hence, we are adopting an approach provided by Smith et al. (2003, 2007) which derives tense interpretations in tenseless languages pragmatically from aspect and contextual information. It accounts for the observed default interpretations by positing that speakers prefer anchoring propositions to the time and world of utterance which privileges present over past and past over future interpretations. Another central result is that we reanalyze the morphological form traditionally categorized as a future tense as a combination of a modal operator $(z \bar{a})$ encoding universal quantification over possible worlds and existential quantification over events and a deficient prospective aspect contributing a future shift of the event time with respect to the reference time. This is in line with recent cross-linguistic insights on future time reference and the future orientation of modals. Beside proposals made for the future markers kelh in St'at'imcets (Matthewson 2006, Rullmann et al. 2008) and -ta in Paraguayan Guaraní (Tonhauser 2011a), which seem to comprise the modal and aspectual meaning components in one morpheme, Matthewson (to appear) reports that Gitksan has a prospective aspect morpheme (dim) which is obligatory for future time reference in general and the future-orientation of modals in particular. Apparently, the prospective in Hausa is associated with the future-orientation of modals in a comparable way (Grubic \& Mucha 2012). Similarly, Kratzer (2012) proposes that a covert prospective aspect is responsible for the future orientation

6 For present lack of counter evidence, we assume that some syntactic slot is providing a time variable $t$ which is assigned its value by the assignment function $g$. Since Hausa does not encode any semantic restriction on the relation between RT and UT (i.e. no tense in the sense of Klein 1994), $g$ can assign past, present or future RTs to the variable depending on the respective context. 
of (circumstantial) modals in English. These findings encourage the conjecture that future-oriented interpretations cross-linguistically involve ET rather than RT shifting and, possibly, modality. Regarding the Hausa future form, however, there are some open questions that need to be addressed in future research. For example, the analysis as it stands would require some default mechanism to bind the open event variable of the prospective in the absence of $z \bar{a}$. The crucial observation that needs to be explained in more detail is that the assumed modal operator $z \bar{a}$ occurs only with the prospective aspect, but the reverse does not hold. Cross-linguistically, Hausa resembles languages like Navajo (Smith et al. 2003, 2007), Chinese (in the analysis of Smith \& Erbaugh 2005) and Paraguayan Guaraní (Tonhauser 2011b) in that it does not have covert tense morphology, rather than St'át'imcets (Matthewson 2006) and Gitksan (Jóhannsdóttir \& Matthewson 2008). However, the data from Hausa suggest that there are still differences between tenseless languages in the pragmatic component. In contrast to Guaraní, future RTs seem to be contextually available in Hausa, while in Guaraní, the accessibility of future RTs is highly restricted as shown in Tonhauser 2011b. We leave this as an interesting subject of future cross-linguistic research.

\section{References}

Abdoulaye, Mahamane L. 2008. Perfectivity and time reference in Hausa. Linguistic Discovery 6. 15-39.

Comrie, Bernard. 1976. Aspect: An Introduction to the Study of Verbal Aspect and Related Problems. Cambridge: Cambridge University Press.

Condoravdi, Cleo. 2002. Temporal interpretation of modals: modals for the present and for the past. In David Beaver, Luis D. Casillas Martìnez, Brady Z. Clark \& Stefan Kaufmann (eds.), The Construction of Meaning, 59-88. Stanford: CSLI publications.

Copley, Bridget. 2009. The Semantics of the Future. New York: Routledge.

Enç, Mürvet. 1996. Tense and modality. In Shalom Lappin (ed.), Handbook of Contemporary Semantic Theory, 345-358.

Grubic, Mira \& Anne Mucha. 2012. Explaining the modal readings of Hausa sai. Presentation given at Modality@Ottawa April 2012, Ottawa.

Jaggar, Philip J. 2001. Hausa. Amsterdam: John Benjamins.

Jóhannsdóttir, Kristín \& Lisa Matthewson. 2008. Zero-marked tense: the case of Gitxsan. In Martin Walkow Emily Elfner (ed.), North East Linguistic Society (NELS) 37, Amherst, MA: GLSA.

Kamp, Hans \& Uwe Reyle. 1993. From Discourse to Logic. Dordrecht: Kluwer. Kaufmann, Magdalena. 2012. Interpreting Imperatives. Heidelberg: Springer. 
Anne Mucha

Kissine, Mikhail. 2008. Why will is not a modal. Natural Language Semantics 16. $129-155$.

Klein, Wolfgang. 1994. Time in Language. New York, London: Routledge.

Kratzer, Angelika. 1998. More structural analogies between pronouns and tenses. In Devon Strolovich \& Aaron Lawson (eds.), Semantics and Linguistic Theory (SALT) 8, Ithaca, N.Y.: CLC publications.

Kratzer, Angelika. 2012. What "can" can mean. Lecture notes, LOT winterschool 2012, Tilburg.

Matthewson, Lisa. 2006. Temporal semantics in a superficially tenseless language. Linguistics and Philosophy 29. 673-713.

Matthewson, Lisa. to appear. On the (non-) future orientation of modals. Sinn und Bedeutung 16.

Newman, Paul. 2000. The Hausa Language. New Haven: Yale University Press.

Partee, Barbara. 1973. Some structural analogies between tenses and pronouns in English. Journal of Philosophy 70. 601-609.

Peterson, Tyler. 2010. Epistemic Modality and Evidentiality in Gitksan at the Semantics-Pragmatics Interface. Vancouver: University of British Columbia dissertation.

Reichenbach, Hans. 1947. Elements of Symbolic Logic. New York: Dover.

Rullmann, Hotze, Lisa Matthewson \& Henry Davis. 2008. Modals as distributive indefinites. Natural Language Semantics 16. 317-357.

Schuh, Russell G. 2003. The functional unity of the Hausa and West Chadic subjunctive. UCLA working papers 9. 17-42.

Smith, Carlota S. \& Mary S. Erbaugh. 2005. Temporal interpretation in Mandarin Chinese. Linguistics 43. 713-756.

Smith, Carlota S., Ellavina Perkins \& Theodore B. Fernald. 2003. Temporal interpretation in Navajo. In Jan Anderssen, Paula Menéndez-Benito \& Adam Werle (eds.), Semantics of Understudied Languages (SULA) 2, 40-71. Amherst, MA: Amherst Working Papers in Linguistics.

Smith, Carlota S., Ellavina Perkins \& Theodore B. Fernald. 2007. Time in Navajo: Direct and indirect interpretation. International Journal of American Linguistics 73. 40-71.

TFS working group. 2011. On the Lam. Totem Field Storyboards retrieved from http://totemfieldstoryboards.org/stories/on_the_lam on May 2, 2012.

Tonhauser, Judith. 2011a. The Paraguayan Guaraní future marker -ta: formal semantics and crosslinguistic comparison. In Renate Musan \& Monika Rathert (eds.), Tense Across Languages, 207-231. Berlin: De Gruyter.

Tonhauser, Judith. 2011b. Temporal reference in Paragyuan Guaraní. Linguistics and Philosophy 34. 257-303.

Vendler, Zeno. 1957. Verbs and Times. Philosophical Review 66. 143-160. 
Temporal Reference in Hausa

Wolff, Ekkehard. 1993. Referenzgrammatik des Hausa. Münster: LIT.

Anne Mucha

Karl-Liebknecht-Strasse 24-25

14476 Potsdam

amucha@uni-potsdam.de 